\title{
EL USO DEL PENSAMIENTO Y DEL MÉTODO CIENTÍFICO EN LA PRÁCTICA PROFESIONAL DEL TRABAJO SOCIAL
}

\section{Milagros Colón Castillo*}

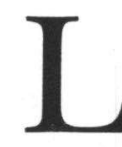

a profesión de Trabajo Social es una de bases sólidas en lo que a marcos de conocimientos se refiere. Cuenta con libros de referencia tales como diccionarios y enciclopedias propios, de exclusividad para la profesión, a la par que con un sin fin de revistas profesionales que mantienen a los/as profesionales al día en las tendencias y discusiones conceptuales que prevalecen en el ejercicio de la misma.

Esta profesión es también una de las más reglamentadas no sólo por la cantidad y calidad de organismos profesionales que la respaldan, sino también por la existencia de un Código de Ética que delinea claramente las conductas a seguir por los/as practicantes de esta disciplina. Sin embargo, aún con todos estos elementos que le dan a la profesión lo necesario para erguirse con orgullo ante el mundo de las profesiones de ayuda, la misma sigue confrontándose con el hecho de tener que defender sus marcos teóricos de referencia. A nuestro juicio, ninguna otra profesión de ayuda tiene que justificar tanto sus acciones, el alcance de su campo de acción y sus posturas ante otras comunidades profesionales y ante la sociedad en general. Probablemente ninguna otra profesión haya tolerado más que la nuestra el que se le impongan ritmos de trabajo y pautas para el cumplimiento de sus tareas. Quisiéramos equivocarnos al

* Catedrática Asociada, Universidad Interamericana, Recinto Metropolitano. 
afirmar que no conocemos otra profesión que tenga más necesidad que la nuestra de estar aclarando sus líneas de acción y evidenciando sus credenciales.

La explicación de por qué esto ocurre puede tener y de hecho tiene raíces históricas e ideológicas. Sin embargo, éstas no son las que ocupan nuestra atención en este trabajo. El mismo sólo pretende recoger unas reflexiones surgidas a lo largo de nuestra labor dentro de la prestación de servicios y de la docencia. Muy particularmente, emanan del análisis crítico de la práctica profesional a la luz de la experiencia en el campo de la investigación científica.

La enseñanza del curso de metodología científica nos ha suscitado serias inquietudes al observar una tendencia en los/as estudiantes a considerar el mismo como uno que únicamente cobra valor cuando se va a realizar un estudio de investigación. Esta inquietud ya ha sido expresada en varias ocasiones por la colega Dra. Antonia Rivera Rivera quien ha estado realizado una labor de concienciación dirigida a ampliar esta conceptualización reduccionista de la investigación.

Este trabajo no pretende en manera alguna analizar exhaustivamente el tema del uso y aplicación de la metodología científica en la práctica cotidiana de la profesión de Trabajo Social. Se limita a una tímida exposición de los puntos que consideramos de mayor relevancia en este tema con la esperanza de que las ideas presentadas tengan el efecto en quienes las deseen recibir, de mantener en su práctica profesional las conductas y actitudes que distinguen a las profesiones basadas en las ciencias del comportamiento. Entre éstas se encuentran la rigurosidad en la selección de métodos y estrategias de intervención; el uso de instrumentos validados para la recopilación de los datos; la aplicación del pensar crítico y analítico que es estimulado por el quehacer científico y la contribución a la documentación de las acciones profesionales como unas fundamentadas en los datos concretos y justificadas por marcos teóricos y conceptuales sometidos a prueba.

Desde el inicio de la intervención profesional, al comienzo de la fase que podemos llamar de exploración de aquella información que necesitamos para conformar el perfil de la situación que tenemos ante nosotros/as, hacemos uso de la metodología científica para recopilar los datos. Estos datos pueden provenir no sólo de la persona que se ha convertido en nuestro/a cliente, sino de todo el escenario que compone el ambiente que le rodea así como de los subsistemas sociales con los cuáles éste/a (el/la cliente) interactúa. 
Las destrezas de observación sistemática, el arte de formular preguntas que nos conduzcan a nuestros propósitos, la habilidad para diseñar formularios que recojan de manera eficiente lo que queremos son indiscutiblemente contribuciones del método científico.

No podemos pasar por alto el hecho de que la investigación científica nos ofrece una oportunidad única en nuestra formación para distinguir entre lo que es conocimiento científico y lo que es conocimiento ordinario y cotidiano. Este último tiene un valor intrínseco puesto que proviene de la experiencia misma de vivir y como producto de la cultura, está íntimamente ligado a nuestra idiosincrasia como pueblo. No se pretende negar el papel tan importante que juega el conocimiento que nos llega de la historia oral, de las tradiciones y costumbres y del folklore. Mucho menos podemos subestimar el sentido común y la intuición como formas que la humanidad ha utilizado desde sus orígenes para resolver problemas y tomar decisiones. Sin embargo, el ejercicio de una profesión requiere de fuentes de conocimiento que produzcan datos certeros, lo más aproximados posibles a la objetividad y que ofrezcan fundamentos válidos y sólidos para respaldar las decisiones profesionales.

Es imprescindible que recordemos que en el trabajo social nuestro objeto de investigación y de intervención es el ser humano y su conducta. Pero más importante aún es que recordemos que al intervenir, lo estamos haciendo con personas que llegan a nosotros en medio del dolor y la angustia. Por eso, y primordialmente por eso, no podemos dar lugar a la improvisación en nuestras acciones. Hacemos énfasis en que no queremos negar la importancia que puede tener la intuición en el análisis que hacemos de una situación o del efecto de las creencias y patrones culturales en nuestro pensar. Lo que queremos significar es que sólo el uso de los conocimientos que nos provee la metodología científica nos puede ayudar a determinar cuándo nos estamos guiando por la intuición, por la cultura, por la autoridad de conocimiento que re reconocemos a otras personas o por los datos que tenemos a nuestro alcance.

Otra contribución de la disciplina investigativa al trabajo social como profesión radica en las destrezas para revisar la literatura y de esa manera obtener provecho del acervo de conocimientos disponible en varias fuentes. A través del desarrollo de estas destrezas podemos buscar de manera sistemática las contribuciones que han hecho diferentes investigaciones en el campo de la conducta humana. Nos nutrimos del avance en el cúmulo de conocimientos teóricos que 
orientan nuestra profesión y nos documentamos en lo relativo a las particularidades de la situación con la cual estamos trabajando. $\mathrm{Si}$ bien la revisión de la literatura no es condición suficiente para mantener los estándares de competencia profesional, sin duda podemos afirmar que es condición necesaria para ello. El no saber y en especial el no querer revisar la literatura como parte de nuestra rutina de trabajo se convierte en sinónimo del anquilosamiento y fosilización que tanto hemos criticado y combatido a través de los años. Tenemos que destacar en este punto la posibilidad de dos terribles implicaciones:

- la de no actualizar la información de nuestros casos o situaciones - esto nos llevaría a implantar un plan de intervención basado en información obsoleta

- la de no actualizar nuestro conocimiento en cuanto a nuevas tendencias o enfoques de la profesión - lo que traería como consecuencia el continuar ejerciendo con marcos que ya no responden a las necesidades de la sociedad contemporánea

La metodología científica tiene además un valor incalculable en tres tareas inherentes al ejercicio de la profesión y dependientes una de la otra: la ponderación o diagnóstico, el diseño de un plan de acción o intervención y la implantación y evaluación del mismo.

No cabe duda de que el desarrollo de impresiones diagnósticas o ponderativas requiere de tres destrezas fundamentales:

- el relacionar la información que tenemos con la que encontramos en la literatura

- relacionar los hechos observados en la situación con las consecuencias que emergen de éstos

- buscar otras posibles relaciones de causa y efecto que se puedan establecer o examinar la solidez de las que se han establecido.

Estas tareas requieren de destrezas elevadas del pensamiento tales como:

- analizar - esto implica descomponer un problema o situación en las partes que lo componen y buscar la relación entre cada una de ellas y entre las mismas y el todo. 
- identificar los puntos opuestos en cada situación - posiblemente en cada situación que trabajemos hay más de una perspectiva posible o puntos de controversia que hay que identificar.

- hacer síntesis - esto requiere el buscar los puntos en común que permitan armonizar o establecer un balance entre lo que la literatura presenta con lo que la experiencia nos ha enseñado.

- evaluar - esto implica el pasar juicio sobre la solidez de nuestras conclusiones y la efectividad de nuestras acciones.

El desarrollo de estas destrezas es uno de los objetivos fundamentales de la metodología científica la cual ha provisto a nuestra disciplina de las herramientas intelectuales que permiten actualizar nuestro quehacer a la luz de las demandas de los tiempos.

El uso continuo y sistemático de la metodología científica nos ofrece una mejor oportunidad para realizar peritaje en los tribunales en caso de ser necesario. Por otro lado, añade mayor probabilidad de hacer intercesión justa por la clientela toda vez que nuestra argumentación está bien fundamentada ya sea por nuestra búsqueda de referencias bibliográficas idóneas o por la recopilación sistemática de información corroborable.

Por último, pero de manera alguna menos importante, las destrezas provistas por la disciplina de la investigación nos ofrecen diversas opciones para evaluar la efectividad de nuestra práctica profesional. Tanto las metodologías cuantitativas como las cualitativas que existen para la medición y evaluación del logro de los objetivos trazados en la intervención constituyen herramientas valiosas al alcance de quien desee ponderar su labor. Los distintos diseños dentro de los estudios de un solo sistema y particularmente, la metodología cualitativa del estudio de caso contribuyen a los propósitos de determinar si hemos sido efectivos y hasta qué grado lo hemos conseguido.

Es responsabilidad también del profesional de trabajo social aportar al desarrollo y aumento del currículo de conocimientos de la propia profesión. Este desarrollo y aumento del acervo teórico puede realizarse simultáneamente con el ejercicio de la misma, al analizar, clasificar y establecer relaciones entre las diferentes situaciones que llegan a la atención del trabajador social. Asimismo, el producto de una práctica profesional realizada en forma consciente y sistemática aporta conocimiento básico de incalculable valor para apoyar y promover cambios estructurales que redundan en medidas de política pública que mejoren la calidad de vida de nuestra clientela. 
Hacemos incapié en que el uso de la metodología científica por sí sola, en manera alguna constituye una garantía de eficiencia en el desempeño de los múltiples roles que se nos adjudican a los/as trabajadores/as sociales. Sin embargo, tenemos razones para creer firmemente en que su integración a través de todo el proceso de ayuda aumenta significativamente la probabilidad de tener éxito en los objetivos trazados para aumentar la calidad de vida de nuestra clientela. Consideramos también que la actitud científica va de la mano con la actitud profesional, son inseparables, y en esa medida, fortalece los cimientos que le dan solidez a la profesión.

\section{Referencias}

Ander-Egg, E. (1995). Técnicas de Investigación Social. (24 ed.). Buenos Aires: Editorial Lumen.

Compton, B.R. \& Galaway, B. (1999). Social Work Processes. (6th ed.). Washington: Brooks/Cole Publishing Company.

Grinnel, R.M. (1997). Social work research and evaluation. (5th ed.). Itasca, Illinois: F.E. Peacock Publishers, Inc.

Hernández Sampieri, R., Fernández Collado, C. Y Baptista Lucio, P. (1991). Metodología de la Investigación. México: McGraw-Hill.

Isaac, S. \& Michael, W.B. (1997). Handbook in research and evaluation. (3th ed.). San Diego, California: EdITS/Educational Testing Service.

Rauch, J.B. (1993). Assessment: A sourcebook for social practice. Milwaukee, Wisconsin: Families International, Inc.

Royse, D. (1995). Research methods in social work. (2nd ed.). Chicago: NelsonHall Publishers.

Shulman, L. (1992). The skills of helping: individuals, families and groups. (3th ed.). Itasca, Illinois: Peacok Publishers, Inc.

Teare, R.J. \& Sheafor, B.W. (1995). Practice.sensitive social work education. Alexandria, Virginia: Council on Social Work Education. 